\title{
Open Access: Concepts, findings, and recommendations for stakeholders in dentistry
}

Fang Hua ${ }^{a^{*}}$, Cenyu Shen ${ }^{b}$, Tanya Walsh ${ }^{a}$, Anne-Marie Glenny ${ }^{a}$, Helen Worthington ${ }^{a}$

${ }^{\text {a }}$ Cochrane Oral Health, Division of Dentistry, School of Medical Sciences, Faculty of Biology, Medicine and Health, The University of Manchester,

Oxford Rd, Manchester M13 9PL, United Kingdom

${ }^{\mathrm{b}}$ Information Systems Science, Hanken School of Economics, Helsinki 00101, Finland

* Corresponding Author:

Fang Hua, Cochrane Oral Health, Division of Dentistry,

The University of Manchester, JR Moore Building,

Oxford Rd, Manchester M13 9PL, United Kingdom.

E-mail address:drfanghua@outlook.com

\section{How to Cite:}

Hua F, Shen C, Walsh T, Glenny AM, Worthington H. Open Access: Concepts, findings, and recommendations for stakeholders in dentistry. Journal of Dentistry, 2017. doi: 10.1016/j.jdent.2017.06.012.

doi: $10.1016 /$ j.jdent.2017.06.012.

PMID: 28669693

Please note that this is a post-print version (after peer-review) for the purpose of self-archiving. Please download the final published version from the publisher's website:

http://www.sciencedirect.com/science/article/pii/S0300571217301574 


\section{ABSTRACT}

Objectives: Open Access (OA) to the scientific literature, a recent revolution in scientific communication, is now required by an increasing number of funders and institutions. The aims of this narrative review are to raise awareness of OA-related concepts and recent research findings among stakeholders in dentistry and to help them make better use of OA and relevant resources.

Data sources: Published journal articles and relevant online materials.

Study selection/results: OA-related definitions and research findings, the approaches to OA, as well as its motivating factors, benefits, 'citation advantage', and mandate policies are introduced. Moreover, the phenomenon of predatory publishing and the status quo of OA in dentistry are discussed. Recommendations are made for stakeholders to avoid and address the hazards of predatory publishing, and for dental researchers to make their work OA in an appropriate manner.

Conclusions/clinical significance: Knowledge about concepts on OA, associated resources and research findings are important for researchers and other users of dental research to make full, appropriate use of OA, and help reduce the avoidable waste caused by inaccessible research. We need more studies into the use and development of OA in dentistry. In addition, joint efforts are required to eliminate the threat of predatory publishing to the dental profession. 


\section{Introduction}

During the past 25 years, developments in information technology, especially the advent of the World Wide Web, have led to a two-phase revolution of scientific communication firstly electronic publishing, and then Open Access (OA) to the scientific literature [1]. With the emergence of an increasing number of open repositories, mandate policies and OA journals, OA is rapidly changing the way researchers disseminate study findings and users (e.g. clinicians, policy-makers) identify / retrieve research evidence. Although the importance of OA has been pointed out in several dental journal editorials [2-6], to our knowledge, OA-related concepts, recent research findings, as well as potential implications have not been reviewed and introduced in a comprehensive way for stakeholders in dentistry. The aims of this narrative review are, therefore, to improve the awareness and knowledge of dental researchers, clinicians, students, educators and policy-makers about $\mathrm{OA}$, and to help them make better use of relevant resources and achieve better performances in this "era of Open Access" [7].

\section{What is Open Access?}

In 2002, the Budapest Open Access Initiative (BOAI) [8], a major international initiative on OA, first used the term "Open Access" and articulated its first public definition [9]:

“By 'open access' to this literature (peer-reviewed research and unreviewed preprints), we mean its free availability on the public internet, permitting any users to read, download, copy, distribute, print, search, or link to the full texts of these articles, crawl them for indexing, pass them as data to software, or use them for any other lawful purpose, without financial, legal, or technical barriers other than those inseparable from gaining access to the internet itself."

One year later, two further OA statements were released: the Bethesda Statement on Open Access Publishing [10] and the Berlin Declaration on Open Access to Knowledge in the Sciences and Humanities [11]. As the definitions used in these two statements were similar to that in the BOAI, they were often referred to as the BBB (Budapest-Bethesda-Berlin) definitions of OA.

However, these definitions, although comprehensive and well articulated, did not distinguish two different components of OA - the "removal of price barriers" and the 
"removal of permission barriers". Therefore, Peter Suber [12], a leading OA expert and proponent, proposed the use of "gratis OA" to indicate free online access (removal of price barriers), and "libre OA" to indicate free online access plus additional re-use rights (removal of price and some / all permission barriers).

\section{The "two roads" to $O A$}

The 2002 BOAI initiative first proposed two complementary strategies to achieve OA: (I) self-archiving and (II) open-access journals [8]. Ten years later, BOAI reaffirmed the effectiveness of these two strategies, but renamed them to take into account changes that had occurred during the past decade: (I) OA through repositories (also called the "Green OA") and (II) OA through journals (the "Gold OA") [9].

\subsection{The "Green road" to $O A$}

Green OA was initially defined as authors' self-archiving of their articles in open repositories [8]. However, with the recent development of Internet and OA mandates, articles can now be archived on authors' personal websites, or in open repositories by institutions / publishers on the authors' behalf. For instance, many publishers have been uploading articles funded by the National Institutes of Health (NIH) to the PubMed Central (PMC) on behalf of authors [13]. Therefore, a more general definition of Green OA as used by Björk et al. [14] may be more appropriate:

"All freely accessible copies of articles, including different versions of said articles, which exist on other web locations than the original publisher's website."

The locations of self-archived articles can generally be categorised into subject-based repositories (e.g. the PMC), institutional repositories (IRs) and other websites (e.g. personal websites / academic social networks, departmental websites, industrial websites). Among these, subject repositories and institutional repositories are usually better locations for self-archiving, because they are maintained by professional librarians, with relevant resources and technologies to ensure the visibility and persistence of archived articles [14]. One example of such mechanisms to improve the visibility of Green OA copies is the OAIster database, a combined catalogue harvesting data from all OAI (Open Archives 
Initiative) compliant repositories / libraries, which as of 2017 includes over 50 million records [15]. The OpenDOAR (Directory of Open Access Repositories; www.opendoar.org) and ROAR (Registry of Open Access Repositories; roar.eprints.org) are two websites providing information about existing open repositories. According to the OpenDOAR, there has been a substantial increase in the number of registered open repositories worldwide, from 902 in 2007 to 3311 in 2016 [16].

To protect their subscription revenue, publishers of subscription-based journals usually only allow authors to self-archive certain versions of their articles, after a set embargo period. Based on articles' content and formats, they are usually categorised into three distinct versions:

- Publisher's version (after copy-editing; also known as the "published article" or "exact copy");

- Author's postprint manuscript (before copy-editing but after peer-review; also referred to as "accepted manuscript"); and

- Author's preprint manuscript (before peer-review; also known as "submitted manuscript").

SHERPA/RoMEO (Securing a Hybrid Environment for Research Preservation and Access/Rights Metadata for Open Archiving; www.sherpa.ac.uk/romeo) is a database of the self-archiving policies of journals and publishers. As of April 2017, 80\% of all 2362 publishers included in this database allow some form of self-archiving [17]. Miguel et al. [18] studied journals registered in Scopus as of April 2010, and found that 57\% of journals in "medicine" and 52\% of those in "areas related to medicine" were subscription journals that did not allow any form of self-archiving. However, in another 2010 analysis by output volume [19], the self-archiving of preprints and postprints was allowed in $79 \%$ and $78 \%$, respectively, of articles published in subscription-based health sciences journals. As a result, at least about $80 \%$ of all research articles published in health sciences journals could be made OA through the Green route alone.

However, the self-archiving of potentially inappropriate versions of articles (versions not allowed by the publishers) has been noticed in previous studies on OA across scientific fields [1] and more specifically in the field of dentistry [20]. In a 2017 study, Jamali [21] found that among subscription-based articles (not published in Gold OA) self-archived on the ResearchGate, about $50 \%$ did not comply with publishers' policy and therefore 
infringed the copyright, of which $98 \%$ were due to the self-archiving of the publisher's version PDFs. Researchers need to be more familiar with publisher's copyright and self-archiving policies and relevant resources (e.g. the SHERPA/RoMEO website) before making their articles Green OA.

\subsection{The "Gold road" to $O A$}

The Gold OA, sometimes also referred to as "publisher-provided OA", is broadly defined as making articles OA through journals or publishers. It can be further subdivided to three types according to the OA policy of journals: "Direct OA", "Hybrid OA" and "Delayed OA" [22].

- "Direct OA" refers to publishing in full immediate OA journals (OAJs), which make all their articles freely available online upon publication (e.g. PLoS One, BMC Oral Health). To cover costs related to editorial workflow, a growing proportion of OAJs require authors (or their funders / institutions) to pay an "article processing charge (APC)" [23]. In 2010, the average value of such APCs was about 1100 USD for OAJs in biomedicine [24]; among authors who published in OAJs in the fields of health sciences, biology and life sciences, an estimated $80 \%$ had their APCs covered by funders or institutions, $8 \%$ used their own funds, $8 \%$ had their APCs waived, and the rest paid the APCs through other means [25]. According to Laakso et al. [22], the number and volume of OAJs have been growing rapidly. Between 2000 and 2009, the average annual growth rate was $18 \%$ for number of journals and $30 \%$ for the number of published articles; in 2009, an estimated $7.7 \%$ of all peer-reviewed articles were published in OAJs. The DOAJ (Directory of Open Access Journals; www.doaj.org) is a major index of legitimate OAJs. As of April 2017, a total of 9358 OAJs are listed in this database, which include 899 medical journals and 93 dental journals [26].

- "Hybrid OA" means those subscription journals that allow authors to make their individual articles OA by paying an optional fee, while keeping the rest of the journals' content available to subscribers only (e.g. Journal of Dentistry, Oral Diseases, Clinical Oral Investigations). After Springer first initiated its "Open Choice" Hybrid OA model (APC: 3000 USD) in 2004 [27], many major publishers followed suit. Based on a study of the five largest publishers, Laakso and Björk [28] found that the number of Hybrid $\mathrm{OA}$ articles published by these publishers increased 
substantially from 666 in 2007 to 13994 in 2013; among all articles published in dental journals that had at least one Hybrid OA article in 2013, an estimated 3.7\% were published using Hybrid OA. Interestingly, although Hybrid OA journals usually have higher APCs than full OAJs, recent studies of authors' APC payment behaviour have indicated a current preference among authors for Hybrid OA journals over OAJs $[29,30]$.

- "Delayed OA" refers to another variant of subscription journals, which keep their latest articles accessible only to subscribers, but make most or all articles automatically OA at the expiry of a set embargo period (e.g. Operative Dentistry, The European Journal of Orthodontics). As there has been no comprehensive index / database for such journals, they were ignored in most previous studies [23]. In a recent explorative analysis of 492 "Delayed OA" journals, Laakso and Björk [31] found that they were substantial in volume and populated with high-impact journals (e.g. Science, New England Journal of Medicine), with 78\% of their articles made OA within 12 months, and $85 \%$ within 24 months. However, these findings may not apply to the field of dentistry. To our knowledge, among the current top-20 high-impact dental journals [32] only one (Operative Dentistry) adopts a Delayed OA model, with an embargo period of 36 months [33].

\subsection{Gold vs. Green}

There has been a debate over which of the two strategies is more cost-effective $[34,35]$. Some claim that Gold OA is the only sustainable model for future publishing, and that governments should allocate funding to promote Gold OA publishing during the current transition period (from fully subscription-based scientific communication to $100 \%$ Gold OA) [36]. Others argue that Green OA is more feasible and reasonable, and that adopting only the Green strategy during the transition will not incur sustainability issues in the future [37-39].

The advantages of Gold OA over self-archiving mainly include:

- Availability upon publication (without any embargo, in the cases of "Direct OA" and "Hybrid OA");

- Removal of permission barriers (with licenses allowing re-use, i.e. "libre OA");

- More reliable content and presentation (especially when compared to author's 
preprints) [40];

- Ensured persistence (with no or low risk of missing documents); and

- No space or length limits for the article (unlike traditional subscription-based printed journals).

Green OA, on the other hand, has the following advantages over Gold:

- Lower costs, at least from the perspective of authors and institutions (the average cost of setting up and maintaining repositories is estimated at between 2 to 53 USD per article, much lower than the average APC of 1100 USD) [14, 24];

- Lower risk of incurring deceptive or irresponsible publishing practices (see Section 8) $[41,42]$; and

- Lower risk of making the available evidence pool biased towards funded studies, which are more likely to be published in OAJs and may have different findings from unfunded studies [25, 43-45].

\section{Motivating factors behind $O A$}

\subsection{Development of the Internet}

Although some have claimed that the OA movement can be traced back to the 1960s [46], modern OA publishing only happened after the advent of the Internet and World Wide Web in the early 1990s [22]. The emergence of electronic journal collections and online bibliographic databases changed the way people use scholarly publications, making them less reliant on printed journals and personal subscriptions $[47,48]$. The Internet also made it possible to substantially decrease the costs of scientific publishing, as those costs for printing and shipping (estimated at $30 \%$ to $80 \%$ of the total budgets of print-based journals) were no longer necessary in an online-only publishing model [49]. In addition, online open repositories for the self-archiving of scientific articles began to emerge. In 1991, the American physicist Paul Ginsparg founded the first of such repositories arXiv.org, which soon became the primary means of communication for physicists $[50,51]$. PubMed Central (PMC), the first and most successful subject-based open repository for biomedical journal literature, was launched by the U.S. National Library of Medicine in $2000[52]$. 


\subsection{The "serials crisis"}

Another major motivating factor for $\mathrm{OA}$ is the financial crisis faced by research libraries, caused by rapidly rising subscription prices for scholarly journals and the relatively static budgets of libraries. During 1986-2005, for those member libraries of the Association of Research Libraries (ARL), their overall subscription expenditures tripled, but the number of purchased items only increased on average $1.9 \%$ per year [53]. Most libraries had to pay more but provide their users with less.

One main reason for the "serials crisis" was the oligopolistic structure of the journal publishing industry, which had resulted in negligible rivalry among major commercial publishers and their high profit margins. Around the year of 2000, it was estimated that Elsevier, Springer and Wiley published about $42 \%$ of all journal articles; and that the average operating profit margin of Elsevier was as high as $36.4 \%$ for their journals in science and medicine [53].

In light of the above, libraries and librarians became the principle advocates of OA. Their efforts have led to the emergence of many major OA organisations [e.g. SHERPA (www.sherpa.ac.uk) and SPARC (Scholarly Publishing and Academic Resources Coalition; www.sparcopen.org)], OA initiatives / statements (e.g. the Bethesda Statement [10]), institutional repositories [54, 55], as well as numerous research studies about OA [56].

\subsection{Ethical and equality issues}

In the traditional pay-to-access publishing model, access to the scientific literature is restricted to those researchers and professionals in wealthy institutions. Coupled with the issue of "serials crisis", subscription (and therefore access) to all journals has become unaffordable to any single individual, library, university or research institution [51]. Such restricted access has lowered the value of research and led to ethical problems.

Firstly, most research projects are funded by citizens through their tax. It is unreasonable that citizens have to pay again to access the research output. Secondly, access to knowledge should be regarded as a human right [57]. Restricted access to scientific knowledge favouring higher income countries is harmful to global human equality [51] and global public health [58]. Thirdly, all peer-reviewed articles are written for the purpose of being used and being built upon by all potential users, not for royalty income of the authors 
or publishers [39]. In this sense, costly subscription fees and limited dissemination of these articles are also against the intentions and efforts of scientists and scholars.

In January 2002, the World Health Organisation (WHO) and six major publishers started the HINARI (Health InterNetwork Access to Research Initiative; www.healthinternetwork.org) programme, which provides local, non-profit institutions in developing countries with free or very low-cost online access to major biomedical journals. In August 2004, the Alliance for Taxpayer Access (ATA; www.taxpayeraccess.org), a coalition of patient groups, physicians, researchers, educational institutions, publishers, and health promotion organisations, was launched in the US to advocate barrier-free access to taxpayer-funded research [46].

\section{Benefits of OA}

Aside from solving the issues mentioned above, OA to the scientific literature is also considered to have additional primary, direct, or indirect benefits.

\subsection{Immediate dissemination}

When an article is published in an OAJ, the final edited content of it after peer-review is available online upon publication. In the case of a preprint, self-archiving upon (or even earlier than) acceptance for publication is allowed by most journals, which means that delay in dissemination due to the editorial process is also avoided. Such early availability and dissemination may improve the time relevance of articles, accelerate the progress of research, and benefit all direct and indirect users of research (e.g. patients) [59, 60].

\subsection{Good findability}

As the metadata of OA articles (usually the full-texts, not just abstracts) are "exposed" on the World Wide Web, they should be easier to identify than non-OA articles, especially when using general search engines like Google [59]. In addition, Green OA copies archived in those repositories that meet interoperability standards (e.g. the OAI protocol) can be easily identified using the search functions of some OA specific databases, such as the OAIster and OpenDOAR. 


\subsection{More downloads}

Several studies have shown that OA articles are downloaded more, and by more people, than non-OA articles. In a randomised controlled trial (RCT) using journals in physiology, Davis et al. [61] found that articles assigned to the OA group received $89 \%$ more full-text downloads, and had $23 \%$ more unique full-text visitors than those assigned to the subscription access group. More recently, based on a study of papers published in Nature Communications, Wang et al. [62] found that OA articles had a greater number of total downloads, that were sustained and consistent for a much longer time than non-OA articles.

\subsection{Broader societal impact}

The emergence and development of "altmetrics" (alternative metrics - a range of measures of research impact that go beyond citations) since 2010 has provided a novel method to measure the societal impact of research articles [63, 64]. Major altmetrics services, such as the Altmetric.com and ImpactStory, have been tracking and analysing the digital use / sharing of articles, based on data collected from policy documents, news outlets, blogs, social media (e.g. Facebook, Twitter), Wikipedia, online reference managers and other sources [65]. Wang et al. [62] compared the Altmetric score of OA and non-OA articles, and found that OA articles received $20 \%$ to $48 \%$ more discussions in social media than non-OA articles.

In addition, increased access to the scholarly literature is beneficial for the fostering of a culture of greater scientific education and literacy, and the improvement of public policies and public engagement in scientific research [51].

\subsection{Reducing research waste}

In 2009, Chalmers and Glasziou [66] estimated that three problems (flawed design, non-publication, and poor reporting) had led to an avoidable waste of $85 \%$ of all research funds in biomedicine, indicating a total global loss of more than 100 billion USD per year. However, when the published report of a research study is not effectively communicated to those who could benefit from it, this research, no matter how well designed and reported, is at least partially wasted. In the case of dental and medical research, the main beneficiaries 
include not only researchers, but also clinicians, patients and policy-makers, who usually have limited access to full articles behind the paywall [67, 68]. Therefore, further development of OA can help provide a comprehensive, accessible and unbiased evidence pool to all stakeholders, and thereby reduce waste in dental and medical research $[69,70]$.

\section{The "citation advantage" of OA}

Another possible benefit of OA, the so-called "citation advantage of OA" (i.e. OA articles receive more citations than non-OA articles), has been one of the main rationales for the OA movement [71]. However, whether this assumption is correct and applies to all scientific disciplines have been under debate $[72,73]$.

In a 2001 study using conference abstracts on computer science and related areas, Lawrence [74] first suggested that OA articles may be cited more than non-OA articles. Thereafter, a total of eight studies [20,61, 72, 75-79] have provided insights into the association between OA and the citation counts of biomedical journal articles (Table 1). Regardless of differences in materials and methods, the OA citation advantage found in these studies ranged from $-5 \%$ to $83 \%$, with three studies [75-77] showing significantly more citations in OA articles. However, in the only study that has looked at this issue in the field of dentistry [20], no evidence was found to support the existence of OA citation advantage. Aside from different research methods used, differences in the findings of these studies could be explained by subject variations, such as different citation behaviour and different level of access to the literature $[51,80,81]$.

In a previous $\mathrm{RCT}$ on this topic, Davis and colleagues $[61,72]$ found that articles assigned to the OA group received significantly more downloads, but no more citations than those assigned to the subscription-access control group. Based on these results, they concluded that the citation advantage reported in earlier studies may be an artefact of other causes (e.g. self-selection), and the main beneficiaries of OA may not be researchers but people outside the research community, who use but rarely contribute to the body of literature.

\section{OA mandates}

Since 2003, an increasing number of institutions, funding bodies and government agencies have released mandatory policies to promote OA. As of April 2017, a total of 769 
OA policies have been registered on the ROARMAP (Registry of Open Access Repository Mandates and Policies; roarmap.eprints.org) website. Among these, $82 \%$ were policies issued by research organisations (or their departments), 10\% by funders, while the rest by funders and research organisations together. A total of $464(60 \%)$ and $150(20 \%)$ policies explicitly required and requested, respectively, the deposit of articles in repositories. Only $134(17 \%)$ recommended the Gold OA, and only $4(1 \%)$ required it. In addition, a majority of the policies were from Europe (60\%), followed by Americas (26\%), Asia (6\%), Oceania $(5 \%)$ and Africa (2\%) [82].

The first department-level institutional OA mandate was implemented by the University of Southampton School of Electronics and Computer Science in January 2003. Then, one year later, the Queensland University of Technology released the first institution-wide OA mandate [83]. In February 2008, the Harvard University (first its Faculty of Arts and Science, then others) began to require Faculty members to deposit their scholarly articles in their institutional repository. This has been one of the most well-known OA mandates, not only because Harvard has a high reputation, but also because the Faculty members granted the University a "non-exclusive, irrevocable, paid-up, worldwide" license, permitting the University to exercise "any and all rights under copyright relating to each of his or her scholarly articles" [84]. Thereafter, such a strategy of rights retention has been adopted by many universities and government agencies, making the provision of Green OA not wholly dependent on publishers' permission [51].

In May 2005, the Wellcome Trust announced its OA plans, requiring that from 1st October 2005 all papers from new research projects be deposited in PMC or UK PMC within 6 months of publication; and that from 1st October 2006 all existing grant holders deposit future papers produced from Trust funding into PMC or UK PMC [85]. One month later, Research Councils UK (including the UK Medical Research Council) released their position statement on access to research outputs, which made it a condition for all grants awarded from 1st October 2005 that a copy of resultant published journal articles or conference proceedings be deposited in and accessible through an OAI compliant repository [86].

In February 2005, the NIH announced its policy on enhancing public access to archived publications resulted from NIH-funded research, requesting that their grantees submit to the PMC the postprint manuscripts upon acceptance for publication, beginning 2nd May 2005 [87]. Three years later, the NIH revised this policy and began to require the 
submission of postprint manuscripts upon acceptance for publication to PMC, so that they can be made publicly available no later than 12 months after the publication date [88]. This mandate policy became another major milestone in the OA movement, because: 1) it was the first OA mandate for a major funding body in the US and the first in the world that was demanded by national legislature; 2) NIH is the world's largest funder of scientific research; and 3) the policy is strongly enforced. When submitting progress reports or applications for new grants, NIH grantees / applicants are required to cite the submission reference number generated by PMC for any of their previous papers covered by the NIH public access policy [89].

According to a previous survey study by Swan and Brown [90], among authors who had not published in OAJs, 69\% indicated that they would self-archive willingly if their employers or funders required them to do so. However, Xia et al. [83] found that only $54 \%$ of repositories showed an increase in the number of deposited items after their OA mandates went into effect. This indicates that merely releasing OA mandate policies, especially in the cases of institutional mandates, may not be enough to change researchers' awareness and practice of self-archiving. Relevant education and assistance, incentives to use repositories, as well as the inclusion of self-archiving into the faculty evaluation system have been recommended as measures accompanying OA mandates [39, 83]. Wording of policy statements is also important. Gargouri et al. [91] graded the (language) strength of institutional mandates on a scale of 1 to 12 and found a significant positive correlation between mandate strength and deposit rate and number.

In 2012, the NIH 2008 mandate had achieved a 75\% compliance rate. However, the compliance rate of the Wellcome Trust 2005 OA policy was estimated at only $55 \%$ at the same timepoint [92]. In light of this, the Wellcome Trust strengthened its OA policy in June 2012: failure to comply with the policy would result in grant payments being withheld and non-compliant publications being discounted in subsequent grant applications [93].

A more recent milestone in the UK was the 2014 HEFCE (Higher Education Funding Council for England) OA policy in relation to research assessments after the 2014 REF (Research Excellence Framework). This policy stated that to be eligible for submission to the next REF, the postprint manuscripts of all journal articles and conference proceedings with an ISSN (International Standard Serial Number), accepted for publication after 1st April 2016, must have been deposited in an institutional or subject repository [94]. While it 
is too early to assess the impact of this policy, in light of the importance of REF assessments to universities and researchers in the UK, a national shift towards better OA adoption can be expected [51].

\section{Predatory OA publishing}

In 2010, Jeffery Beall, an academic librarian at the University of Colorado Denver, coined the term "predatory" publishers to refer to "dishonest publishers that publish counterfeit journals to exploit the author-pays OA model" [41, 95]. However, according to Moher and Moher [96], currently there is no robust definition for predatory publishers / journals, and they are best identified through behaviour and practice. Typically, they send spam emails inviting researchers to submit (or serve on editorial boards) [97, 98], provide little or no peer review [99], have unprofessional websites full of grammatical and spelling errors [100], use fake information about impact factors and/or the editors [101], hide requirement of APCs or charge very low APCs (mostly below150 USD) [102, 103], and use "European" or "American" in the journal titles and/or addresses but actually are based at some developing countries such as India [99, 103].

In a sting operation in 2013, journalist John Bohannon [99] submitted a concocted, seriously flawed paper to 304 OAJs: as many as 157 (52\%) journals accepted the article; only 36 journals gave review comments that had recognised the article's scientific problems, 16 of which accepted the article despite reviewers' criticism. More recently, Pisanski et al. [101] submitted a fake application for an editorial position to 360 journals, and found that $33 \%$ of potential predatory journals appointed the fictitious unqualified scientist as an editor. Shen and Björk [103] carried out an investigation of the volume and market characteristics of predatory OA publishing during 2010 to 2014. They found that the number of active predatory journals increased rapidly from around 1,700 to 8,000, and the number of articles published in these journals rose from 53,000 to an estimated 420,000; a majority of identified predatory publishers and authors who published in predatory journals were from India and several other countries in Asia and Africa.

\subsection{Consequences of predatory publishing}

Predatory publishing has deleterious effects on scholarly communication and the development of science, which is largely dependent upon the dissemination and accumulation of ethical, reliable, and high-quality research.

First, the existence of predatory publishers is promoting unethical behaviours of researchers [41]. Not all authors who publish in predatory journals are tricked into doing 
this. It is believed that many of them chose deliberately to use predatory journals because their manuscripts are of poor quality (and thus rejected by mainstream journals); some do this to publish plagiarised work, or articles that falsely support the efficacy of certain medicines / devices $[95,104]$. In the fields of medicine and dentistry, scientific literature forms the crucial evidence base of clinical practice and public health policy-making. Therefore, articles published in predatory journals not only mislead future research, but also pollute the evidence base and harm the quality of health care [100, 105],

Second, publishing in predatory journals is harmful to researchers' career: they do not have the opportunity to improve their articles through decent peer review [99]; their work may become "lost science" (as predatory journals are usually not discoverable through standard searches and tend to disappear) $[95,105]$; and their chances of getting promotion and recognition may be compromised by a tainted curricular vitae $[6,41]$.

In addition, legitimate OAJs (usually referred to as "scholarly OAJs") are also victims of predatory publishing: they are often confused with predatory journals [105]; and to compete with the latter, they have to promise faster editorial processes and lower APCs, which may make it difficult for them to maintain high standards in quality control [41].

\subsection{Potential measures to address predatory publishing}

During the past few years, many editors of leading medical [105-107] and dental journals [6] have published editorials to raise the awareness of predatory publishers. Although these editorials have served as a very important first step [108], more concerted efforts are needed from all stakeholders of scientific communication to stop the problems of predatory publishing [96].

Beall emphasised that all users of research, especially clinicians and health sciences researchers, need to acquire the "scholarly publishing literacy" (i.e. the ability to recognise and avoid publishing scams) [100]. In 2010, he started to publish on his blog ("Scholarly Open Access") a regularly updated blacklist of "potential, possible or probable" predatory publishers and OAJs (the "Beall's list"), which included only 18 publishers in 2010 [109] but 1155 in 2017 [110]. While this blacklist has been a valuable tool for predatory publisher identification and used widely by researchers [101-103], it has also received a lot criticisms from both potential predatory publishers and other OA experts [99, 109, 111]. For unknown reasons, Beall withdrew his blacklist on 17 January 2017 [110].

Nevertheless, there are several whitelists available that can be used to help judge the legitimacy of journals. Aside from the lists of journals indexed in reputable bibliographic databases such as the Web of Science (Journal Citation Reports) and MEDLINE [112, 113], the DOAJ is a major whitelist specifically for OAJs. Though not a $100 \%$ fail-safe [101], 
the DOAJ is currently the most comprehensive and helpful tool available [114]. It has high standards for inclusion and is regularly updated, with newly qualified journals added and questionable journals delisted $[26,115]$.

In addition, some medical specialties have developed their own whitelists for stakeholders in the fields. For instance, in 2014, the International Academy of Nursing Editors (IANE) released a position paper to raise the awareness of predatory publishers, and started to maintain an online, weekly updated list of vetted nursing journals ("Directory of Nursing Journals") for nurse authors [116]. Table 2 lists a series of actions that can be undertaken by key stakeholders in dentistry to disarm the threat of predatory publishing to the dental profession $[96,105,117-121]$.

\section{Current situation of $O A$ in dentistry}

So far there have been only two research studies about OA in the field of dentistry. Hua et al. [20] assessed the OA status of 908 PubMed-indexed dental articles published during 2013, and found that $46 \%$ of them were freely available online in 2015. Among articles that were OA, 53\% were available from publishers (Gold OA) and 74\% were available through self-archiving (Green OA). Half of all Gold OA articles were published in OAJs (i.e. Direct OA), and the other half in subscription-based journals (i.e. Hybrid or Delayed OA). Most Green OA articles were available at the ResearchGate (73\%) or PMC (23\%). In addition, Google Scholar was the most effective search engine to identify OA copies of dental journal articles, followed by PubMed LinkOut, Google and the "Publications" search tool of ResearchGate.

Tahim et al. [122] studied the OA policy of 30 SCIE-indexed, oral and maxillofacial surgery-related journals (including implant dentistry and head and neck surgery), and found that three (10\%) of these journals were full OAJs, twenty (67\%) were Hybrid OA, and the rest $(23 \%)$ did not offer researchers any OA publishing services. They made a comparison of the impact factor and level of evidence (LOE) between journals offering OA publishing (both OAJs and Hybrid OA journals) and the others, and found no significant differences.

\section{Conclusions and recommendations}

The knowledge and understanding of OA-related concepts, resources and main research findings are important for dental researchers and other users of dental research to make full, appropriate use of OA and avoid the harms of predatory publishing. Based on the literature reviewed in this article, we recommend a series of steps for dental researchers to take when making their articles OA (Fig. 1). Mainly, researchers should familiarise themselves with 
the OA policies of their funders and institutions first, and then choose a legitimate and appropriate journal to submit their manuscripts. It is the researchers' responsibility to make sure their methods of achieving OA meet the requirements of funders and institutions and do not infringe the rights of publishers. In addition, we need more research to provide insights into the use and development of OA in the field of dentistry. All stakeholders should be aware of the problem of predatory publishers, and make joint efforts to eliminate their threat to the dental profession. 


\section{References}

[1] B.C. Bjork, P. Welling, M. Laakso, P. Majlender, T. Hedlund, G. Gudnason, Open access to the scientific journal literature: Situation 2009, PLoS One 5(6) (2010) e11273.

[2] M.T. Cobourne, Open access orthodontics, J Orthod 40(2) (2013) 91-2.

[3] E. Cohen, A.Y. Chen, R.L. Ferris, A. Lee, J. Bernier, Open Access in biomedical sciences: What the current turning point means more specifically to Oral Oncology contributors and readers, Oral Oncol 49(10) (2013) 985-986.

[4] G.P. Garlet, The Journal of Applied Oral Science and the open science era, J Appl Oral Sci 21(1) (2013).

[5] M. Smith, C. O'Dell, Open Access to research findings and Community Dental Health, Community Dent Health 32(1) (2015) 2-3.

[6] M. Glick, Publish and perish, J Am Dent Assoc 147(6) (2016) 385-387.

[7] S.M. Brower, Medical education and information literacy in the era of open access, Med Ref Serv Q 29(1) (2010) 85-91.

[8] Open Society Institute, Read the Budapest Open Access Initiative, 2002. http://www.budapestopenaccessinitiative.org/read. (Accessed 5 Oct 2016).

[9] Open Society Institute, Ten years on from the Budapest Open Access Initiative: setting the default to open, 2012. http://www.budapestopenaccessinitiative.org/boai-10-recommendations. (Accessed 5 Oct 2016).

[10] The Bethesda Statement Group, Bethesda statement on Open Access publishing, 2003. http://legacy.earlham.edu/ peters/fos/bethesda.htm. (Accessed 19 Jan 2017).

[11] The Berlin Declaration Group, Berlin declaration on Open Access to knowledge in the sciences and humanities, 2003. https://openaccess.mpg.de/Berlin-Declaration. (Accessed 19 Jan 2017).

[12] P. Suber, Gratis and Libre Open Access, 2008. http://sparcopen.org/our-work/gratis-and-libre-open-access/. (Accessed 19 Jan 2017).

[13] PubMed Central, NIH public access and PMC, 2015. https://www.ncbi.nlm.nih.gov/pmc/about/public-access-info/ - p5. (Accessed 22 Jan 2017).

[14] B.C. Bjork, M. Laakso, P. Welling, P. Paetau, Anatomy of Green Open Access, J Assoc Inf Sci Tech 65(2) (2014) 237-250.

[15] Online Computer Library Center, The OAlster database - Overview, 2017. http://www.oclc.org/en/oaister.html. (Accessed 6 Apr 2017).

[16] OpenDOAR, Growth of the OpenDOAR database - Worldwide, 2017. http://www.opendoar.org/find.php?format=charts. (Accessed 6 Apr 2017). 
[17] SHERPA/RoMEO, Statistics for the 2362 publishers in the RoMEO database, 2017. http://www.sherpa.ac.uk/romeo/statistics.php?la=en\&fIDnum=\%7C\&mode=simple.

(Accessed 6 Apr 2017).

[18] S. Miguel, Z. Chinchilla-Rodriguez, F. de Moya-Anegon, Open Access and Scopus: A new approach to scientific visibility from the standpoint of access, J Am Soc Inf Sci Tec 62(6) (2011) 1130-1145.

[19] M. Laakso, Green open access policies of scholarly journal publishers: a study of what, when, and where self-archiving is allowed, Scientometrics 99(2) (2014) 475-494.

[20] F. Hua, H. Sun, T. Walsh, H. Worthington, A.-M. Glenny, Open Access to Journal Articles in Dentistry: Prevalence and Citation Impact, Journal of dentistry 47 (2016) 41-48.

[21] H.R. Jamali, Copyright compliance and infringement in ResearchGate full-text journal articles, Scientometrics 112(1) (2017) 1-14.

[22] M. Laakso, P. Welling, H. Bukvova, L. Nyman, B.C. Bjork, T. Hedlund, The development of open access journal publishing from 1993 to 2009, PLoS One 6(6) (2011) e20961.

[23] M. Laakso, B.C. Bjork, Anatomy of open access publishing: a study of longitudinal development and internal structure, BMC Med 10 (2012) 124.

[24] D.J. Solomon, B.C. Bjork, A study of open access journals using article processing charges, J Am Soc Inf Sci Tec 63(8) (2012) 1485-1495.

[25] D.J. Solomon, B.C. Bjork, Publication fees in Open Access publishing: sources of funding and factors influencing choice of journal, J Am Soc Inf Sci Tec 63(1) (2012) 98-107. [26] DOAJ, About DOAJ, 2017. https://doaj.org/about. (Accessed 6 Apr 2017).

[27] Springer, Open Choice: Springer adds new publication model, 2004. http://www.springer.com/about+springer/media/pressreleases?SGWID=0-11002-2-80357 7-0. (Accessed 21 Jan 2017).

[28] M. Laakso, B.C. Bjork, Hybrid open access - A longitudinal study, J Informetr 10(4) (2016) 919-932.

[29] S. Pinfield, J. Salter, P.A. Bath, The "total cost of publication" in a hybrid open-access environment: Institutional approaches to funding journal article-processing charges in combination with subscriptions, J Assoc Inf Sci Tech 67(7) (2016) 1751-1766.

[30] D. Solomon, B.C. Bjork, Article processing charges for open access publication-the situation for research intensive universities in the USA and Canada, PeerJ 4 (2016) e2264.

[31] M. Laakso, B.C. Bjork, Delayed open access: An overlooked high-impact category of openly available scientific literature, J Am Soc Inf Sci Tec 64(7) (2013) 1323-1329.

[32] Thomson Reuters, 2015 Journal Citation Reports ${ }^{\circledR}$ Science Edition, 2016. https://jcr.incites.thomsonreuters.com/JCRJournalHomeAction.action. (Accessed $6 \mathrm{Apr}$ 2017). 
[33] Operative Dentistry, A complete guide to manuscript requirements, 2014. https://www.jopdent.com/authors/authors.html. (Accessed 7 Apr 2017).

[34] A. O'Dowd, Experts disagree on whether cost of publishing research will fall, as open access grows, MPs hear, Br Med J 346(2013) f2502.

[35] R. Van Noorden, Britain aims for broad open access, Nature 486(7403) (2012) 302-303.

[36] Working Group on Expanding Access to Published Research Findings, Accessibility, sustainability, excellence: how to expand access to research publications, 2012. https://www.acu.ac.uk/research-information-network/finch-report-final. (Accessed 20 Jan 2017).

[37] M. Frank, Open but not free - Publishing in the 21st century, N Engl J Med 368(9) (2013) 787-789.

[38] S. Harnad, T. Brody, F. Vallieres, L. Carr, S. Hitchcock, Y. Gingras, C. Oppenheim, C. Hajjem, E.R. Hilf, The access/impact problem and the green and gold roads to open access: An update, Serials Rev 34(1) (2008) 36-40.

[39] S. Harnad, Ethics of open access to biomedical research: just a special case of ethics of open access to research, Philos Ethics Humanit Med 2 (2007) 31.

[40] E. Tabor, Prepublication culture in clinical research, Lancet 387(10020) (2016) 750.

[41] J. Beall, Predatory publishers are corrupting open access, Nature 489(7415) (2012) 179.

[42] D.N. Salem, M.M. Boumil, Conflict of interest in Open-Access publishing, N Engl J Med 369(5) (2013) 491.

[43] G. de Jong, Reasons to temper enthusiasm about open access nursing journals, Contemp Nurse 53(2) (2017) 262-266.

[44] L. Bero, F. Oostvogel, P. Bacchetti, K. Lee, Factors associated with findings of published trials of drug-drug comparisons: Why some statins appear more efficacious than others, PLoS Med 4(6) (2007) 1001-1010.

[45] S.S. Liyanage, C.R. Maclntyre, Do financial factors such as author page charges and industry funding impact on the nature of published research in infectious diseases?, Health Info Libr J 23(3) (2006) 214-222.

[46] Open Access Directory, Timeline of the open access movement, 2015. http://oad.simmons.edu/oadwiki/Timeline. (Accessed 20 Jan 2017).

[47] E.T. Smith, Changes in faculty reading behaviors: The impact of electronic journals on the University of Georgia, J Acad Libr 29(3) (2003) 162-168.

[48] C. Tenopir, D.W. King, S. Edwards, L. Wu, Electronic journals and changes in scholarly article seeking and reading patterns, Aslib Proc 61(1) (2009) 5-32. 
[49] V. Resh, Science and communication: an author/editor/user's perspective on the transition from paper to electronic publishing, Issues in Science \& Technology Librarianship (19) (1998) 1092-1206.

[50] D. Butler, The writing is on the Web for science journals in print, Nature 397(6716) (1999) 195-200.

[51] J.P. Tennant, F. Waldner, D.C. Jacques, P. Masuzzo, L.B. Collister, C.H. Hartgerink, The academic, economic and societal impacts of Open Access: an evidence-based review, F1000Research 5 (2016) 632.

[52] I. Masic, K. Milinovic, On-line biomedical databases-the best source for quick search of the scientific information in the biomedicine, Acta Inform Med 20(2) (2012) 72-84.

[53] G.S. McGuigan, R.D. Russell, The business of academic publishing: A strategic analysis of the academic journal publishing industry and its impact on the future of scholarly publishing, E-JASL 9(3) (2008) 1.

[54] S. Chang, Institutional repositories: the library's new role, Digit Libr Perspect 19(3) (2003) 77-79.

[55] L. Horwood, S. Sullivan, E. Young, J. Garner, OAl compliant institutional repositories and the role of library staff, Library Management 25(4/5) (2004) 170-176.

[56] J. Grandbois, J. Beheshti, A bibliometric study of scholarly articles published by library and information science authors about open access, Inform Res 19(4) (2014) 648.

[57] J. Willinsky, The access principle: The case for open access to research and scholarship, MIT Press, Cambridge, Mass., 2006.

[58] G. Yamey, Excluding the poor from accessing biomedical literature: a rights violation that impedes global health, Health Hum Rights 10(1) (2008) 21-42.

[59] E. Giglia, Open access to scientific research: where are we and where are we going? Facts and figures on the occasion of the 2010 Open Access Week (October 18-24), Eur J Phys Rehabil Med 46(3) (2010) 461-469.

[60] C. Livas, N. Pandis, Y.J. Ren, Time relevance, citation of reporting guidelines, and breadth of literature search in systematic reviews in orthodontics, Eur J Orthod 37(2) (2015) 183-187.

[61] P.M. Davis, B.V. Lewenstein, D.H. Simon, J.G. Booth, M.J.L. Connolly, Open access publishing, article downloads, and citations: randomised controlled trial, $\mathrm{Br}$ Med J 337(2008) a568.

[62] X.W. Wang, C. Liu, W.L. Mao, Z.C. Fang, The open access advantage considering citation, article usage and social media attention, Scientometrics 103(2) (2015) 555-564.

[63] R. Kwok, Research impact: Altmetrics make their mark, Nature 500(7463) (2013)

491-3. 
[64] J. Kolahi, P. Iranmanesh, S. Khazaei, Altmetric analysis of 2015 dental literature: a cross sectional survey, Br Dent J 222(9) (2017) 695-699.

[65] J. Kolahi, S. Khazaei, Altmetric: Top 50 dental articles in 2014, Br Dent J 220(11) (2016) $569-74$.

[66] I. Chalmers, P. Glasziou, Avoidable waste in the production and reporting of research evidence, Lancet 374(9683) (2009) 86-89.

[67] L.L. Moorhead, C. Holzmeyer, L.A. Maggio, R.M. Steinberg, J. Willinsky, In an Age of Open Access to Research Policies: Physician and Public Health NGO Staff Research Use and Policy Awareness, PLoS One 10(7) (2015) e0129708.

[68] K. Kurata, T. Morioka, K. Yokoi, M. Matsubayashi, Remarkable growth of open access in the biomedical field: analysis of PubMed articles from 2006 to 2010, PLoS One 8(5) (2013) e60925.

[69] P. Glasziou, The role of open access in reducing waste in medical research, PLoS Med 11(5) (2014) e1001651.

[70] A.W. Chan, F. Song, A. Vickers, T. Jefferson, K. Dickersin, P.C. Gotzsche, H.M. Krumholz, D. Ghersi, H.B. van der Worp, Increasing value and reducing waste: addressing inaccessible research, Lancet 383(9913) (2014) 257-266.

[71] Y. Gargouri, C. Hajjem, V. Lariviere, Y. Gingras, L. Carr, T. Brody, S. Harnad, Self-selected or mandated, open access increases citation impact for higher quality research, PLoS One 5(10) (2010) e13636.

[72] P.M. Davis, Open access, readership, citations: a randomized controlled trial of scientific journal publishing, FASEB J 25(7) (2011) 2129-2134.

[73] G. Eysenbach, Citation advantage of open access articles, PLoS Biol 4(5) (2006) e157.

[74] S. Lawrence, Free online availability substantially increases a paper's impact, Nature 411(6837) (2001) 521.

[75] P.M. Davis, Author-Choice Open-Access Publishing in the Biological and Medical Literature: A Citation Analysis, J Am Soc Inf Sci Tec 60(1) (2009) 3-8.

[76] S.L. De Groote, M. Shultz, N.R. Smalheiser, Examining the Impact of the National Institutes of Health Public Access Policy on the Citation Rates of Journal Articles, PLoS One 10(10) (2015) e0139951.

[77] V.C. Lansingh, M.J. Carter, Does open access in ophthalmology affect how articles are subsequently cited in research?, Ophthalmology 116(8) (2009) 1425-1431.

[78] C. Hajjem, S. Harnad, Y. Gingras, Ten-Year Cross-Disciplinary Comparison of the Growth of Open Access and How it Increases Research Citation Impact, 2006. https://arxiv.org/abs/cs/0606079. (Accessed 31 Jan 2017).

[79] L. Xu, J. Liu, Q. Fang, Analysis on open access citation advantage: an empirical study 
based on Oxford open journals, 2011 iConference, Association for Computing Machinery, Seattle, Washington, USA, 2011, pp. 426-432.

[80] I.D. Craig, A.M. Plume, M.E. McVeigh, J. Pringle, M. Amin, Do open access articles have greater citation impact? A critical review of the literature, J Informetr 1(3) (2007) 239-248.

[81] M. Zitt, S. Ramanana-Rahary, E. Bassecoulard, Relativity of citation performance and excellence measures: From cross-field to cross-scale effects of field-normalisation, Scientometrics 63(2) (2005) 373-401.

[82] ROARMAP, How many Open Access policies are there worldwide?, 2017. http://roarmap.eprints.org/dataviz2.html. (Accessed 9 Apr 2017).

[83] J.F. Xia, S.B. Gilchrist, N.X.P. Smith, J.A. Kingery, J.R. Radecki, M.L. Wilhelm, K.C. Harrison, M.L. Ashby, A.J. Mahn, A review of Open Access self-archiving mandate policies, Portal-Libr Acad 12(1) (2012) 85-102.

[84] A. Albanese, Harvard mandates Open Access, Libr J 133(5) (2008) 16-17.

[85] Wellcome Trust, Wellcome Trust announces Open Access plans, 2005. https://wellcome.ac.uk/press-release/wellcome-trust-announces-open-access-plans.

(Accessed 28 Jan 2017).

[86] Research Councils UK, RCUK position statement on access to research outputs, 2005.

[87] National Instututes of Health, Policy on enhancing public access to archived publications resulting from NIH-funded research, 2005. https://grants.nih.gov/grants/guide/notice-files/NOT-OD-05-022.html. (Accessed 28 Jan 2017).

[88] National Instututes of Health, Revised Policy on Enhancing Public Access to Archived Publications Resulting from NIH-Funded Research, 2008. https://grants.nih.gov/grants/guide/notice-files/NOT-OD-08-033.html. (Accessed 28 Jan 2017).

[89] P. Suber, An open access mandate for the National Institutes of Health, Open Med 2(2) (2008) e39-41.

[90] A. Swan, S. Brown, Authors and open access publishing, Learn Publ 17(3) (2004) 219-224.

[91] Y. Gargouri, V. Lariviere, Y. Gingras, T. Brody, L. Carr, S. Harnad, Testing the Finch hypothesis on Green OA mandate ineffectiveness, 2012. http://eprints.soton.ac.uk/344687/. (Accessed 29 Jan 2017).

[92] R. Poynder, Open Access mandates: Ensuring compliance, 2012. http://poynder.blogspot.co.uk/2012/05/open-access-mandates-ensuring.html. (Accessed 29 Jan 2017). 
[93] Wellcome Trust, Wellcome Trust strengthens its open access policy, 2012. https://wellcome.ac.uk/press-release/wellcome-trust-strengthens-its-open-access-policy. (Accessed 28 Jan 2017).

[94] Higher Education Funding Council for England, Open access research, 2014. http://www.hefce.ac.uk/rsrch/oa/Policy/. (Accessed 29 Jan 2017).

[95] J. Beall, Predatory open-access scholarly publishers, Charlest Advis 11(4) (2010) 10-17.

[96] D. Moher, E. Moher, Stop Predatory Publishers Now: Act Collaboratively, Ann Intern Med 164(9) (2016) 616-617.

[97] D. Moher, A. Srivastava, You are invited to submit... BMC Med 13 (2015).

[98] A. Grey, M.J. Bolland, N. Dalbeth, G. Gamble, L. Sadler, We read spam a lot: prospective cohort study of unsolicited and unwanted academic invitations, Br Med J 355 (2016).

[99] J. Bohannon, Who's Afraid of Peer Review?, Science 342(6154) (2013) 60-65.

[100] J. Beall, Medical publishing triage - chronicling predatory open access publishers, Ann Med Surg 2(2) (2013) 47-9.

[101] P. Sorokowski, E. Kulczycki, A. Sorokowska, K. Pisanski, Predatory journals recruit fake editor, Nature 543(7646) (2017) 481-483.

[102] J.F. Xia, Predatory journals and their article publishing charges, Learn Publ 28(1) (2015) 69-74.

[103] C.Y. Shen, B.C. Bjork, 'Predatory' open access: a longitudinal study of article volumes and market characteristics, BMC Med 13 (2015) 230.

[104] J. Beall, Medical publishing and the threat of predatory journals, Int J Womens Dermatol 2(4) (2016) 115-116.

[105] J. Clark, R. Smith, Firm action needed on predatory journals, Br Med J 350 (2015).

[106] C. Haug, The Downside of Open-Access Publishing, N Engl J Med 368(9) (2013) 791-793.

[107] R.E. Bartholomew, Science for sale: the rise of predatory journals, J R Soc Med 107(10) (2014) 384-385.

[108] M.M. Christopher, K.M. Young, Awareness of "Predatory" Open-Access Journals among Prospective Veterinary and Medical Authors Attending Scientific Writing Workshops, Front Vet Sci 2(22) (2015).

[109] J. Beall, Predatory publishing is just one of the consequences of gold open access, Learn Publ 26(2) (2013) 79-84.

[110] D.S. Chawla, Mystery as controversial list of predatory publishers disappears, 2017. http://www.sciencemag.org/news/2017/01/mystery-controversial-list-predatory-publishe 
rs-disappears. (Accessed 11 Apr 2017).

[111] M. Bloudoff-Indelicato, Backlash over journals blacklisting, Nature 526 (2015) 613.

[112] T.E. Stone, R.C. Rossiter, Predatory publishing: Take care that you are not caught in the Open Access net, Nurs Health Sci 17(3) (2015) 277-9.

[113] B. Hansoti, M.I. Langdorf, L.S. Murphy, Discriminating Between Legitimate and Predatory Open Access Journals: Report from the International Federation for Emergency Medicine Research Committee, West J Emerg Med 17(5) (2016) 497-507.

[114] M.S. Liljekvist, K. Andresen, H.C. Pommergaard, J. Rosenberg, For 481 biomedical open access journals, articles are not searchable in the Directory of Open Access Journals nor in conventional biomedical databases, PeerJ 3 (2015) e972.

[115] M. Baker, Open-access index delists thousands of journals, 2016. http://www.nature.com/news/open-access-index-delists-thousands-of-journals-1.19871. (Accessed 10 Apr 2017).

[116] L.H. Nicoll, Predatory Publisher Statement, Comput Inform Nurs 33(2) (2015) 43-45.

[117] World Association of Medical Editors, Principles of Transparency and Best Practice in Scholarly Publishing,

2015. http://www.wame.org/about/principles-of-transparency-and-best-practice. (Accessed 12 Apr 2017).

[118] F. Hua, T. Walsh, H. Worthington, A.M. Glenny, "Predatory" Publishing and Open Access in Dentistry, J Am Dent Assoc 147(8) (2016) 600-601.

[119] D. Moher, D.G. Altman, Four Proposals to Help Improve the Medical Research Literature, PLoS Med 12(9) (2015) e1001864.

[120] E. Wager, Why we should worry less about predatory publishers and more about the quality of research and training at our academic institutions, J Epidemiol 27(3) (2017) 87-88.

[121] J. Beall, Ban predators from the scientific record, Nature 534(7607) (2016) 326-326.

[122] A. Tahim, H. Bansal, A.M. Goodson, K.F. Payne, S. Sabharwal, Open Access Publishing: A Study of Current Practice in Oral and Maxillofacial Surgery Research, J Maxillofac Oral Surg 15(4) (2016) 517-520. 


\section{Tables}

Table 1. Previous studies on the citation advantage of OA in biomedical fields.

\begin{tabular}{|c|c|c|c|c|c|c|}
\hline Study & Sample / sub-sample ${ }^{a}$ & $\begin{array}{c}\text { Source of } \\
\text { citation data }\end{array}$ & $\begin{array}{l}\text { Follow-up } \\
\text { (months) }\end{array}$ & $\begin{array}{c}\text { Citation } \\
\text { advantage }\end{array}$ & $\begin{array}{c}\text { Primary statistical } \\
\text { analysis }\end{array}$ & $\begin{array}{c}\text { Confounding variables } \\
\text { adjusted for }\end{array}$ \\
\hline $\begin{array}{l}\text { Hajjem et } \\
\text { al. } 2006 \\
{[78]^{\text {b }}}\end{array}$ & $\begin{array}{c}\text { Around } 80,000 \text { health related articles } \\
(6 \% \text { OA vs. } 94 \% \text { non-OA, determined } \\
\text { using software) published during } 1992 \text { to } \\
2003\end{array}$ & $\begin{array}{l}\text { CDROM } \\
\text { version } \\
\text { SCI/SSCI } \\
\text { database }\end{array}$ & $\begin{array}{l}\text { Not } \\
\text { reported }\end{array}$ & $+57 \%$ & Descriptive only & None \\
\hline $\begin{array}{l}\text { Davis et al. } \\
2008[61]\end{array}$ & $\begin{array}{l}1619 \text { articles ( } 247 \text { randomly assigned to } \\
\text { OA vs. } 1372 \text { assigned to non-OA) } \\
\text { published during January to April } 2007 \\
\text { in } 11 \text { physiological journals }\end{array}$ & $\begin{array}{l}\text { Web of } \\
\text { Science }\end{array}$ & 9 to 12 & $\begin{array}{c}-5 \% \\
(95 \% \mathrm{CI},-19 \% \\
\text { to }+10 \% \\
\mathrm{P}=0.484)\end{array}$ & $\begin{array}{l}\text { Negative binomial } \\
\text { regression } \\
\text { (journal as a } \\
\text { random variable) }\end{array}$ & $\begin{array}{c}\text { Self-archiving, publication } \\
\text { date, cover article, review } \\
\text { article, methods article, } \\
\text { press release, Log(authors), } \\
\text { Log(pages), } \\
\text { Log(references), any author } \\
\text { from USA, impact factor }\end{array}$ \\
\hline $\begin{array}{c}\text { Davis } 2009 \\
\quad[75]^{\mathbf{c}}\end{array}$ & $\begin{array}{c}982 \mathrm{OA} \text { articles and } 6525 \text { non-OA } \\
\text { articles published during } 2004 \text { to } 2007 \text { in } \\
11 \text { Hybrid and Delayed OA journals ( } 9 \text { in } \\
\text { biomedicine, } 2 \text { in plant sciences) }\end{array}$ & $\begin{array}{l}\text { Web of } \\
\text { Science }\end{array}$ & 18 to 57 & $\begin{array}{c}+11 \% \\
(95 \% \mathrm{CI},+6 \% \text { to } \\
+17 \% ; \mathrm{P}<0.001)\end{array}$ & $\begin{array}{c}\text { Linear regression } \\
\text { (journal as a random } \\
\text { variable) }\end{array}$ & $\begin{array}{l}\text { Months after publication, } \\
\text { Ln(authors), Ln(references), } \\
\text { Ln(pages), review article, } \\
\text { corresponding author USA, } \\
\text { journal section, cover } \\
\text { article }\end{array}$ \\
\hline $\begin{array}{l}\text { Xu et al. } \\
2011[79]^{c}\end{array}$ & $\begin{array}{c}840 \text { Direct or Delayed OA articles vs. } \\
8401 \text { non-OA articles, published in } 61 \\
\text { medical journals in } 2009\end{array}$ & $\begin{array}{l}\text { Google } \\
\text { Scholar }\end{array}$ & 6 to 18 & $\begin{array}{c}\quad+83 \% \\
\text { (mean } 6.69 \text { vs. } \\
3.66 \text { times) }\end{array}$ & Descriptive only & None \\
\hline
\end{tabular}


Table 1. Previous studies on the citation advantage of OA in biomedical fields (continued).

\begin{tabular}{|c|c|c|c|c|c|c|}
\hline Study & Sample / sub-sample & $\begin{array}{c}\text { Source of } \\
\text { citation data }\end{array}$ & $\begin{array}{c}\text { Follow-up } \\
\text { (months) }\end{array}$ & $\begin{array}{c}\text { Citation } \\
\text { advantage }\end{array}$ & $\begin{array}{c}\text { Primary } \\
\text { statistical } \\
\text { analysis }\end{array}$ & $\begin{array}{c}\text { Confounding variables } \\
\text { adjusted for }\end{array}$ \\
\hline $\begin{array}{l}\text { Lansingh } \\
2009[77]^{\mathbf{c}}\end{array}$ & $\begin{array}{l}225 \text { OA and } 225 \text { non-OA articles in } \\
\text { ophthalmology retrieved from PubMed, } \\
\text { published before December } 2003\end{array}$ & Scopus & $\approx 54$ & $\begin{array}{c}+32 \% \\
\text { (mean } 15.2 \text { vs. } 11.5 \\
\text { times; } \mathrm{P}=0.048)\end{array}$ & $\begin{array}{l}\text { Generalised linear } \\
\text { model analysis }\end{array}$ & $\begin{array}{l}\text { Number of authors, } \\
\text { subject area, review } \\
\text { article, geographic origin, } \\
\text { language, funding }\end{array}$ \\
\hline $\begin{array}{l}\text { Davis } 2011 \\
\quad[70]\end{array}$ & $\begin{array}{l}515 \text { articles (113 randomly assigned to } \\
\text { OA vs. } 402 \text { assigned to non-OA) } \\
\text { published during June to December } 2007 \\
\text { in } 5 \text { cardiology journals and } 1 \text { neurology } \\
\text { journal }\end{array}$ & Web of Science & 36 & $\begin{array}{c}1.21 \\
(\mathrm{OR} ; \mathrm{P}=0.55)\end{array}$ & $\begin{array}{l}\text { Logistic } \\
\text { regression } \\
\text { (journal as a } \\
\text { random variable) }\end{array}$ & None \\
\hline $\begin{array}{l}\text { De Groote } \\
\text { et al. } 2015 \\
{[72]^{\mathrm{c}}} \\
\end{array}$ & $\begin{array}{l}4382 \text { NIH funded articles ( } 3119 \text { deposited } \\
\text { in PMC vs. } 1263 \text { not deposited in PMC) } \\
\text { published in } 2009 \text { in } 122 \text { medical journals }\end{array}$ & Scopus & 60 & $\begin{array}{c}+22 \% \\
\text { (mean } 29.1 \text { vs. } 23.9 \\
\text { times; } \mathrm{P}=0.011) \\
\end{array}$ & $\begin{array}{l}\text { ANOVA analysis } \\
\text { blocked for } \\
\text { journal }\end{array}$ & None \\
\hline $\begin{array}{l}\text { Hua et al. } \\
2016[20]\end{array}$ & $\begin{array}{l}416 \mathrm{OA} \text { and } 492 \text { non-OA articles in } \\
\text { dentistry retrieved from PubMed, } \\
\text { published during } 2013\end{array}$ & $\begin{array}{c}\text { Web of } \\
\text { Science, } \\
\text { Scopus, Google } \\
\text { Scholar }\end{array}$ & 17 to 29 & $\begin{array}{c}1.12 \\
\text { (OR; } 95 \% \mathrm{CI}, 0.79 \\
\text { to } 1.59 ; \text { median } \\
1.33 \text { vs. } 1.33 \text { times; } \\
\mathrm{P}=0.52)\end{array}$ & $\begin{array}{l}\text { Logistic } \\
\text { regression }\end{array}$ & $\begin{array}{l}\text { Subject area, study type, } \\
\text { geographic origin }\end{array}$ \\
\hline
\end{tabular}

CI, confidence interval; OR, odds ratio.

${ }^{\text {a }}$ For studies that had a more general scope, only the sub-sample related to biomedicine is described.

${ }^{\mathbf{b}}$ Non peer-reviewed study report.

${ }^{\mathbf{c}}$ Authors did not check, either manually or with software, whether articles in the non-OA group were Green OA elsewhere on the Internet. 
Table 2. Recommendations to key stakeholders in dentistry to address the issue of predatory publishing [96, 105, 117-121].

\begin{tabular}{|c|c|}
\hline Stakeholder & Recommendation \\
\hline Researchers & $\begin{array}{l}\text { - Be aware of the hazards of predatory journals and relevant resources that can be used to identify them (e.g. the Directory of } \\
\text { Open Access Journals, Journal Citation Reports) } \\
\text { - View all invitations to submit (or to serve on editorial boards) with caution } \\
\text { - Avoid the citation of articles published in predatory journals } \\
\text { - Carry out research about predatory dental journals and authors publishing in them }\end{array}$ \\
\hline $\begin{array}{l}\text { Users of research (e.g. dental } \\
\text { professionals, patients) }\end{array}$ & $\begin{array}{l}\text { - Be aware of the hazards of predatory journals and relevant resources that can be used to identify them (e.g. the Directory of } \\
\text { Open Access Journals, Journal Citation Reports) }\end{array}$ \\
\hline Legitimate dental journals & $\begin{array}{l}\text { - Raise the awareness of predatory publishing through editorials and official websites (e.g. journal instructions, online } \\
\text { educational materials) } \\
\text { - Follow the principles of transparency and best practice in scholarly publishing (www.wame.org/policies-and-resources) } \\
\text { and avoid editorial misconduct } \\
\text { - Legitimate dental OAJs should make sure that they are included in the Directory of Open Access Journals }\end{array}$ \\
\hline Funders & $\begin{array}{l}\text { - Raise the awareness of predatory publishing through official websites } \\
\text { - Forbid the use of their funds to cover predatory journal APCs }\end{array}$ \\
\hline $\begin{array}{c}\text { Academic organisations / } \\
\text { professional societies }\end{array}$ & $\begin{array}{l}\text { - Raise the awareness of predatory publishing through official websites and existing conferences / workshops } \\
\text { - Organise conferences / seminars dedicated to tackling predatory publishing } \\
\text { - Collaborate to maintain an online, regularly updated whitelist of vetted, legitimate dental journals }\end{array}$ \\
\hline
\end{tabular}




\section{Figure}

Before submission, select an appropriate OA strategy (Gold or Green) according to:

- Your funder and institution's OA requirements (e.g. venue of publishing / self-archiving, version of articles, length of embargo)

- Your funding options for $O A$ publishing (e.g. grants from funders, institutional central funds)

- Your personal preferences

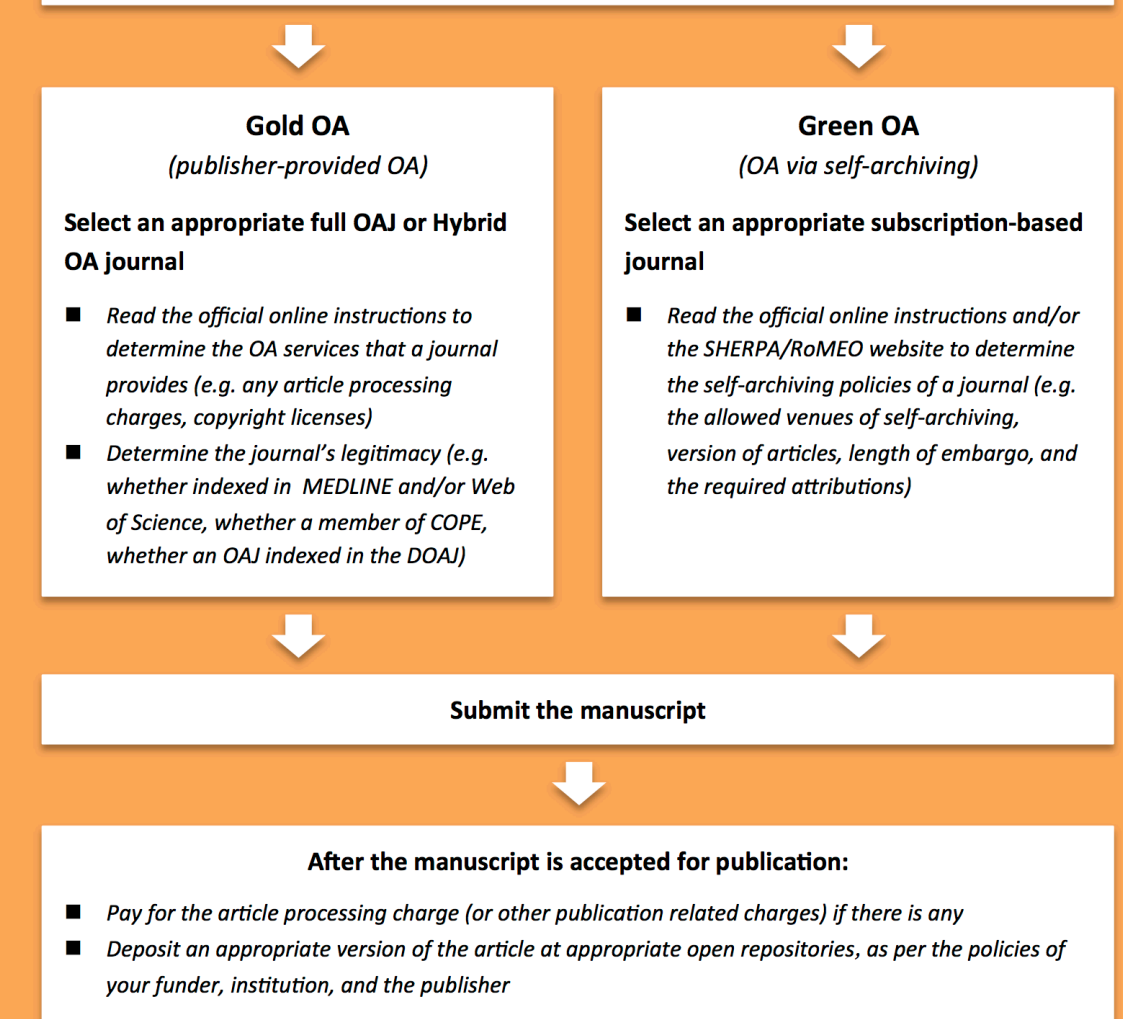

Fig. 1. Recommended steps for making a research article OA. OA, open access; OAJ, open access journal; COPE, Committee on Publication Ethics (www.publicationethics.org); DOAJ, Directory of Open Access Journals (www.doaj.org); SHERPA/RoMEO, Securing a Hybrid Environment for Research Preservation and Access/Rights Metadata for Open Archiving (www.sherpa.ac.uk/romeo). 